\title{
Colonial Growth in Agar of Cells Derived from Neoplastic and Non-Neoplastic Tissues of Children
}

\author{
R.M.MaAllister ${ }^{[14]}$ and George Reed \\ Departments of Pediatrics and Pathology, University of Southern California School of Medicine, \\ and The Childrens Hospital, Los Angeles, California, USA
}

\section{Extract}

Explants from 14 of 29 solid tumors of children formed colonies in soft agar, as did trypsin-dispersed cells from 9 of 17 solid tumors. The histologic characteristics of the colonies of 8 tumors were similar to those of the tumor from which they were derived. Colonies from 5 of the tumor cultures did not induce tumors when transplanted into adolescent hamsters.

Gells from the bone marrow of 14 children with acute leukemia did not form colonies in agar.

Cells from none of 5 normal human fetal tissues formed colonies; explants from 4 of 7 hyperplastic but not neoplastic tissues formed colonies in agar. The agar culture method is useful in cultivating human cancer cells; it cannot be used to differentiate neoplastic from hyperplastic cells.

\section{Speculation}

The present studies indicate that cells from certain human cancers form colonies in soft agar medium. This culture method gives a selective growth advantage to cancer cells and may be useful for in vitro studies of the biology of human cancer.

\section{Introduction}

Previous studies in this laboratory indicated that cells derived from hamster tumors induced by certain adenoviruses formed colonies in soft agar medium; cells from normal hamster tissues did not [8]. These colonies had histologic characteristics similar to those of the tumor from which they were derived and induced progressively growing tumors when transplanted into adolescent hamsters.

These findings suggested that human tumor cells might form colonies in agar which were histologically similar to the parent tissue and that these colonies might induce tumors in hamsters.

The findings also suggested that the agar culture method might differentiate neoplastic from non-neoplastic tissues. The present paper describes studies of human tumor cells cultured in soft agar medium.
Materials and Methods

The techniques used for the cultivation in agar medium of cells derived from adenovirus-induced hamster tumors have been reported [8] and were used with minor modifications. Specimens of solid tumors or of normal tissues were minced to $1 \mathrm{~mm}$ in diameter, washed in Hank's balanced salt solution, and cultured in agar as explants or as trypsin-dispersed cells. Fifteen to 20 tissue explants were suspended in $1.5 \mathrm{ml}$ of $0.33 \%$ agar containing $10 \%$ calf serum and $10 \%$ tryptose phosphate broth in Eagle's medium (soft agar). This mixture was pipetted onto a preset base of $7 \mathrm{ml}$ of $0.5 \%$ agar in $60 \mathrm{~mm}$ petri dishes and incubated at $37^{\circ}$ in a well-humidified incubator constantly flushed with $5 \%$ $\mathrm{CO}_{2}$ in air.

The trypsin-dispersed cells were cultured in agar as follows: To each of 5 tubes containing either $10^{7}, 10^{6}$ 
or $5 \times 10^{5}$ cells was added $1.5 \mathrm{ml}$ of soft agar. The contents of each tube was seeded onto a dish containing a preset agar base.

Bone marrow aspirates were obtained from children with leukemia before they had received antileukemic therapy. Nucleated cells from the aspirates were separated by light centrifugation. These cells were cultured in agar by the method employed for the trypsindispersed cells from solid tumors.

The methods of subcultivation of the colonies, as well as the techniques employed for the histologic studies of colonies, have been previously described [8]. Sources of neoplastic tissue specimens and non-neoplastic tissue specimens are listed in table I.

\section{Results}

Several days after plating tumor explants in agar medium, cells migrated from the edges of explants; by 14 days, a halo of cells surrounded the explant. After a 20-day period of cultivation in agar, numerous cells were noted in the agar medium between the explants of all tumors except in the case of an optic glioma and of a neuroblastoma. In addition, colonies approximately 0.2 to $1 \mathrm{~mm}$ in diameter had formed in cultures of 14 of 29 of the tumors: 3 brain tumors, 3 hepatoblastomas, 3 Wilms' tumors, 2 lymphomas (lymphosarcoma and Hodgkin's disease), 1 sarcoma consistent with rhabdomyosarcoma, 1 neuroblastoma, and 1 papillary renal adenocarcinoma (fig. 1). These colonies were distinguished by their shape from the explants. The former were round; the latter usually irregularly shaped. The colonies presumably were formed by the multiplication of cells on the periphery of small tumor fragments or cell clumps present in the original tumor mince seeded in the agar medium. The average number of colonies per dish varied from a few (in cultures of a hepatoblastoma and of an astrocytoma) to 38 (cultures of the renal adenocarcinoma). A number of minute colonies, not scored in these data and seen with the aid of a low-power microscope, were also present in many cultures.

Trypsin-dispersed cells from 17 tumors were cultivated in soft agar. Cells from 9 tumors (3 Wilms' tumors, 2 ependymomas, 2 sarcomas, 1 glioma-hemangioblastoma and 1 embryonal carcinoma) yielded visible colonies 0.1 to $0.2 \mathrm{~mm}$ in diameter after a 20-day period of cultivation (fig. 2). The efficiency of colony formation for each of these tumors was low; average colony count in 5 dishes seeded with $10^{6}$ tumor cells ranged from 133 (an ependymoma) to 1 (a Wilms' tumor).

When removed from the agar and placed in liquid medium in plastic petri dishes, colonies from 13 tumors
Table I. Source of tissue specimens cultivated in agar

\begin{tabular}{ll}
\hline Sources of tissue specimens & $\begin{array}{l}\text { Specimens } \\
\text { producing } \\
\text { colonies/ } \\
\text { total specimens } \\
\text { cultivated }\end{array}$ \\
\hline
\end{tabular}

Solid tumor specimens

Wilms' tumors

$5 / 9$

Brain tumors

$\begin{array}{ll}\text { Astrocytoma, Grade I cerebellar } & 1 / 1 \\ \text { Ependymomas } & 2 / 3\end{array}$

Optic glioma $\quad 0 / 1$

Piloid astrocytoma $\quad 1 / 2$

Glioma-hemangioblastoma $\quad 1 / 1$

Neuroblastomas $\quad 1 / 5$

Hepatoblastomas $\quad 3 / 3$

Sarcomas consistent with rhabdomyosarcoma

Malignant lymphomas (lymphosarcoma and Hodgkin's disease) $\quad 2 / 2$

Ewing's sarcoma $\quad 0 / 1$

Embryonal carcinoma 1/1

Papillary renal adenocarcinoma $\quad 1 / 1$

Undifferentiated malignant neoplasm $\quad 0 / 1$

Neurofibroma

Neurolemmoma

$\frac{0 / 1}{20 / 37}$

Leukemic bone marrow specimens ${ }^{2}$

Acute lymphocytic leukemia $\quad 0 / 9$

Acute myelocytic leukemia $\quad 0 / 3$

Acute monocytic leukemia $\quad 0 / 1$

Acute undifferentiated leukemia $\quad \frac{0 / 1}{0 / 14}$

Non-neoplastic tissue specimens

Normal human fetal tissues (skin-muscle, kidney, thymus, tonsil, lung)

Other tissues

Mesenteric lymph nodes (mesenteric adenitis)

Hyperplastic lymph nodes

Spleen (fatal lymphohistiocytosis)

$2 / 4$

Cystic hygroma

$1 / 1$

$\frac{0 / 1}{4 / 12}$

1 The first number indicates those specimens cultivated in agar which produced colonies $0.1 \mathrm{~mm}$ or greater in size; the second number indicates the total number of specimens cultivated in agar either as explants or monodispersed cells for each particular class of tumor or tissue. See text for further description.

2 Each specimen from a different patient with untreated leukemia of the cited cell type. 


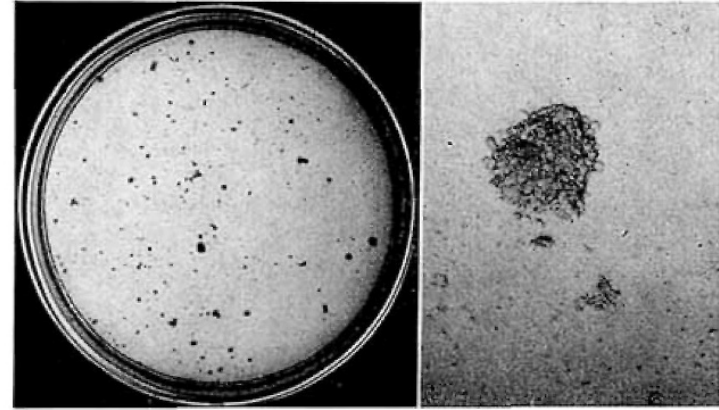

Fig. 1. Low-power view of soft agar culture plate, twothirds actual size, showing colony formation 20 days after seeding; refer to text for the size of colony scored. Fig. 2. Colony of cells derived from an ependymoma, 20 days after cultivation in agar. $\times 30$.

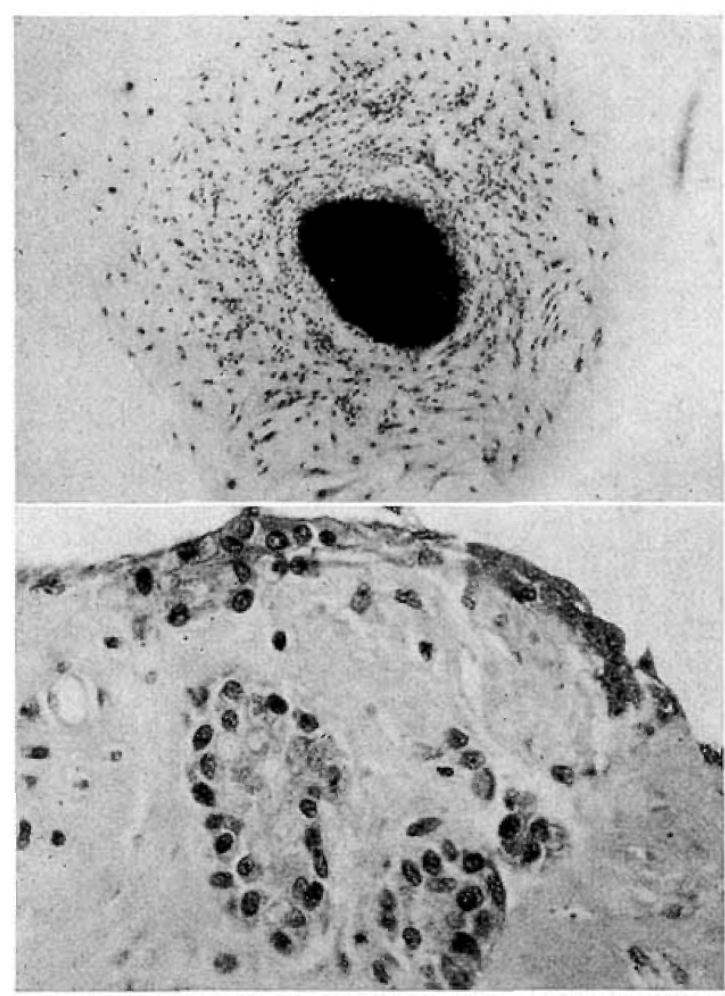

Fig.3. Cell colony of an ependymoma cultivated in agar for 11 days and then removed from agar and subcultivated under liquid medium in a plastic petri dish. Note outgrowth of cells. Photographed after a 20-day period of cultivation under liquid medium. Giemsa stain. $\times 90$.

Fig.4. Colony of hepatoblastoma; the tumor cells were cultivated in agar 24 days. Note tubular and acinar formation and fibrous stroma in the core of the colony. Hematoxylin and Eosin stain (H. and E.). $\times 300$. attached to the plastic surface and cells migrated from them (fig. 3). None of these subcultures has yielded an established line of tumor cells. The cultural requirements of freshly isolated tumor cells are under intensive study [10].

Cells from none of the 14 leukemic bone marrow specimens grew as colonies in agar. Small clumps of cells (presumably marrow fragments) appeared in cultures of cells from 3 leukemic patients ( 2 with acute myelocytic leukemia, 1 with acute undifferentiated leukemia). None of these cell clumps grew following subcultivation in liquid medium.

Four of the 12 specimens of diseased non-neoplastic tissues formed colonies in agar. All of these colonies were derived from tissue explants; explants were from an inflamed lymph node from a patient with mesenteric adenitis (average, 11 colonies/dish), from 2 hyper-

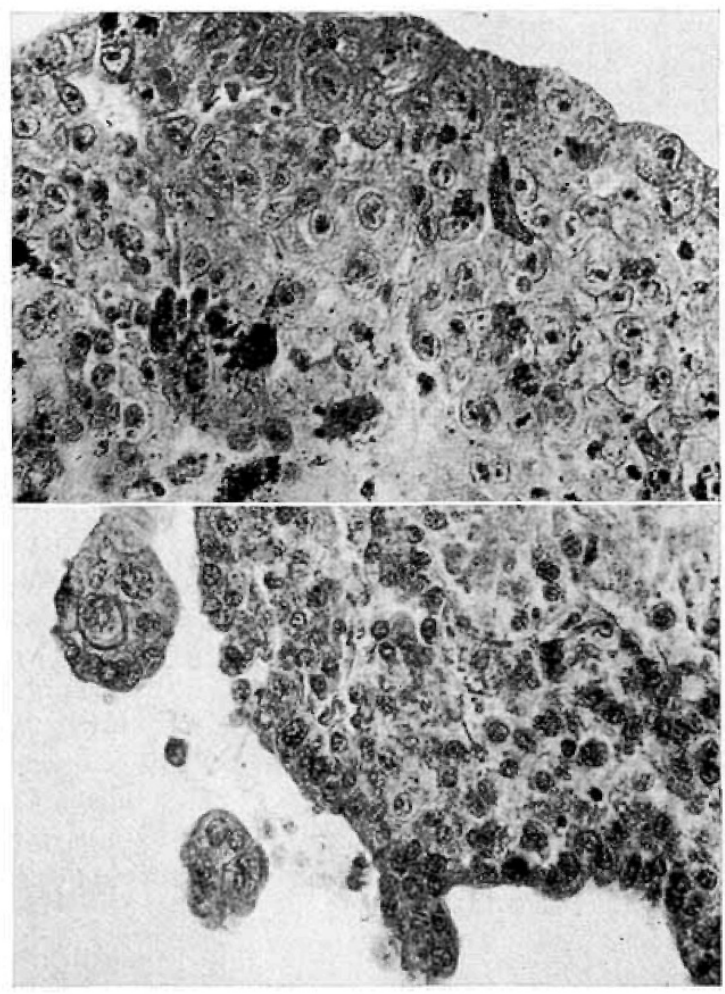

Fig. 5. Colony of hepatoblastoma from another patient. The edge of the colony shows pigment production and mitoses; obtained after 21 days of cultivation in agar. H. and E. $\times 350$.

Fig. 6. Colony of papillary renal adenocarcinoma with papillae at the edges of the colony; obtained after 10 days of cultivation in agar. H. and E. $\times 300$. 
plastic lymph nodes (average, 3 and 9 colonies/dish) and from the spleen of a patient with fatal lymphohistiocytosis (average, 38 colonies/dish).

Colonies from the 2 hyperplastic nodes and the spleen yielded fibroblast-like cells following subcultivation under liquid medium.

Histological studies were made on 9 tissue colony specimens ( 8 neoplastic tissues and 1 non-neoplastic tissue). The colonies from the 8 neoplastic tissues were examined 10-28 days after cultivation in agar and showed histologic characteristics comparable to those of the tumor from which they were derived (figs. 4-6).

Ten to 28 days after cultivation in agar, colonies of one each of the 3 hepatoblastomas (figs. 4-5) were forming pigment, collagen, and mitotic figures, respectively. The cell colonies were comparable to the histologic pattern and cell type of the original surgical specimen and of the tumors at autopsy.

An uncommon tumor in the pediatric age group, the papillary renal adenocarcinoma, maintained its papillary pattern in the cell colonies (fig.6).

Four colonies from each of 5 tumors (2 Wilms' tumors, hepatoblastoma, renal adenocarcinoma, and sarcoma) and 2 hyperplastic lymph nodes were picked from the agar and transplanted subcutaneously or intraperitoneally into adolescent hamsters. None induced tumors during an 8-week period of observation.

\section{Discussion}

Normal cells apparently have a step in their mitotic cycle which requires anchorage and elongation on a solid substrate such as glass, plastic or cotton wool and, therefore, cannot grow when suspended in agar medium [10] unless, as reported for certain mouse cells, an underlying feeder layer of cells is provided [2, 9]. In contrast, certain cancer cells do not have such a requirement and can form colonies in agar medium without a feeder layer. Colonial growth in agar medium has been reported for HeLa and Hep 2, two established lines of human cancer cells [4], as well as for adenovirus-induced hamster tumor cells [8] and cells transformed in vitro by polyoma virus [4], Rous sarcoma virus [3], $\mathrm{SV}_{40}$ [11], and adenovirus 12 [6].

The present studies demonstrate that cells from certain solid tumors form colonies in agar medium without a feeder layer. That the colonies were viable and growing was suggested by the presence of mitotic figures (fig. 5) and papillary formations (fig.6). The colonies yielded cells after subcultivation in liquid medium, thus confirming viability.

The histologic characteristics of the cell colonies of 8 human tumors growing in agar medium were comparable to those of the tumor from which they were derived. This is in marked contrast to previous studies in which cultivation of tumor cells in vitro under liquid medium yielded primarily fibroblast-like cells $[1,5,7]$.

None of the colonies of the 5 tumors tested induced tumors when inoculated into adolescent hamsters and thus did not behave like cell colonies of certain adenovirus-induced tumor cells [8].

Although cells from none of 5 normal human fetal tissues formed colonies, cells from 4 diseased but nonneoplastic tissues did form colonies in soft agar. The agar method did not, therefore, differentiate between cells of the human tumors tested and cells of the hyperplastic tissues tested. In these studies, the normal fetal tissues did not specifically match the diseased tissues; however, the types of cells, lymphocytes and plasmacytes, present in the normal fetal thymus and tonsil did match the cellular components of 4 diseased tissues that formed colonies.

These results indicate that the agar culture method is a useful technique for cultivation of certain solid tumors. Further studies are in progress to determine whether lines of human cancer cells, free of stromal cells, can be established from the colonies.

\section{Summary}

Cells from certain solid tumors, but not leukemic cells, form colonies in agar. The histological characteristics of these colonies are similar to those of the tumor from which they were derived. None of the colonies tested induced tumors in hamsters. Cells from certain diseased but non-neoplastic tissues formed colonies in agar; cells from normal human fetal tissues did not.

\section{References and Notes}

1. Ang, B.; Jaross, L. and McAllister, R. M. : Studies of fibroblast-like cells from the bone marrow of leukemic and nonleukemic children. Proc. Soc. exp. Biol., N.Y. 109: 467 (1962).

2. Bradley, T.R. and Metcalf, D.: The growth of mouse bone marrow cells in vitro. Austr. J. exp. Biol. med. Sci. 44: 287 (1966).

3. MAGPherson, I.: Reversion in hamster cells transformed by Rous sarcoma virus. Science 148: 1731 (1965).

4. Macpherson, I. and Montagnier, L.: Agar suspension culture for the selective assay of cells transformed by polyoma virus. Virology 23: 291 (1964).

5. MaAllister, R.M.; Landing, B.H. and GoodHEART, C.R.: Isolation of adenoviruses from neoplastic and non-neoplastic tissues of children. Lab. Invest. 13: 894 (1964). 
6. MaAllister, R.M. and Macpherson, I.: Transformation of a hamster cell line by adenovirus 12 . J.gen.Virol. 2: 99 (1968).

7. MaAllister, R. M.; Mrkenas, M.; Straw, R. M. and Landing, B. H.: Cytologic and virologic studies of cultures derived from neoplastic and nonneoplastic tissues of children. Lab. Invest. 12: 343 (1963).

8. MaAllister, R.M.; Reed, G. and Huebner, R. $\mathrm{J}$.: Colonial growth in agar of cells derived from adenovirus-induced hamster tumors. J. nat. Cancer Inst. 39: 43 (1967).

9. Pluznik, D. H. and SAchs, L.: The cloning of normal 'mast' cells in tissue culture. J. cell. comp. Physiol. 66: 319 (1966).

10. RuBin, H.: The behavior of cells before and after virus-induced malignant transformation. The Harvey Lecture Series 61, 1965-1966 (Academic Press, New York 1967).
11. VAN Der NoordaA, J. and Enders, J.F.: Early effects by $\mathrm{SV}_{40}$ on growth in vitro of hamster and human tissue cells. Proc. Soc. exp. Biol., N.Y. 122: 1144 (1966).

12. The authors wish to thank Drs. William H. SNyDER (surgery), Denman Hammond (hematology), and Benjamin H.LAnding (pathology) for their help in these studies, and Mrs. SophIE Kaplan, Mrs. Margot Nickle, Mrs. Mary Peer, Mrs. Lianne Wilcox, and Mr. James Dixon for their technical assistance.

13. This investigation was supported in part by USPHS research grants CA-02649 and CA-04865 from the National Cancer Institute and by research grant E-196 from the American Cancer Society.

14. Requests for reprints should be addressed to: RoBert M. MaAllister, M.D., Ghildrens Hospital of Los Angeles, P. O. Box 54700 Terminal Annex, Los Angeles, Cal. 90054 (USA). 